\title{
Anti-Mycobacterium leprae antibodies induced by lepromin injection as demonstrated by indirect immunofluorescence
}

\author{
ELBA GONZÁLEZ-ABREU, \\ A GONZÁLEZ-SEGREDO \& F DE LA CRUZ \\ Departamento de Microbiologia, Instituto de Medicina Tropical \\ 'Pedro Kouri', Calle 200 y Avenida 15. Siboney, Ciudad Habana, \\ Cuba
}

Accepted for publication 30 May 1984

\begin{abstract}
Summary In Cuba the Mitsuda test is carried out on all household contacts of leprosy patients as a measure of epidemiological control. Hence, we need to know whether positivity in the FLA-ABS test can be caused by lepromin testing. The present study shows that sera from healthy individuals were positive by the FLA-ABS test up to 180 days after lepromin testing. The highest positivity rate was reached by day 21 , and the highest antibody level by day 45 .
\end{abstract}

\section{Introduction}

The development of a suitable test for infection has long been awaited by those engaged in leprosy control. Sensitive serological tests capable of demonstrating antibodies reacting specifically with Mycobacterium leprae may become valuable for the diagnosis of early infections and if used in parallel with the lepromin test, for the identification of individuals infected but unable to develop an efficient immune response.

A number of scientists have searched for sensitive and specific techniques to detect subclinical infection in leprosy. ${ }^{1-4}$ In 1981 the fluorescent leprosy antibody absorption (FLA-ABS) test of Dr Masahide Abe et al. ${ }^{4}$ was established in our laboratory. Since then we have been working with this technique and our first results ${ }^{5}$ correspond with those of Abe and other investigators. ${ }^{6,}{ }^{7}$ However, for a wider use in epidemiological studies the test should be sensitive enough to be positive in individuals who have been subclinically infected with M. leprae, whether or not this exposure leads to clinical disease. ${ }^{8}$

In Cuba, all leprosy contacts are given a lepromin test as one of several measures of epidemiological control. ${ }^{9}$ Therefore we need to know whether 
positivity in the FLA-ABS test can be caused by lepromin testing. We report here the levels of antibodies induced by lepromin, and the duration of their presence.

\section{Materials and methods}

The FLA-ABS test was carried out in 37 healthy persons with no known contact with leprosy. Lepromin, $0.1 \mathrm{ml}\left(3.4 \times 10^{7}\right.$ bacilli $\left./ \mathrm{ml}\right)$ prepared from human leproma in our laboratory, was injected intradermally. Five millilitre blood samples were taken from each subject before, 21, 45, 90, 180 and 365 days after the lepromin injection. The sera obtained were used in the FLA-ABS test as described by Abe et al. ${ }^{6}$ Abe's criteria of positivity were used to analyse the results. The sera obtained from the same group of persons before the lepromin injection were considered a negative control ( 0 time group) and all comparisons refer to this group. The serum of a confirmed lepromatous leprosy patient with an antibody titre of more than 1:2500 was used as positive control and was included in all the experiments.

A fluorescent Olympus microscope, model BHF, with interference filter (FITC) was used and the smears were observed under $\times 400$ magnification.

\section{Results}

The results obtained after lepromin injection can be seen in Table 1 and previous results obtained with lepromatous patients and a group of household contacts are

Table 1. FLA-ABS results according to time after lepromin injection

\begin{tabular}{cccccccccc}
\hline $\begin{array}{c}\text { Time } \\
\text { (days) }\end{array}$ & $n^{*}$ & Positive & $\%$ & $-1: 40$ & $1: 160$ & $1: 640$ & $1: 2560$ & $\begin{array}{c}\text { Geometric } \\
\text { mean }\end{array}$ & SD \\
\hline 0 & $34 \dagger$ & 0 & 0 & 0 & 0 & 0 & 0 & - & - \\
21 & 32 & 28 & $87 \cdot 5$ & 2 & 15 & 8 & 3 & 288 & $2 \cdot 93$ \\
45 & 30 & 18 & $60 \cdot 0$ & 3 & 5 & 6 & 4 & 372 & $4 \cdot 05$ \\
90 & 33 & 7 & $21 \cdot 2$ & 5 & 0 & 0 & 2 & 132 & $6 \cdot 55$ \\
180 & 33 & 3 & $9 \cdot 09$ & 2 & 1 & 0 & 0 & $63 \cdot 1$ & 1.92 \\
365 & 34 & 0 & 0 & 0 & 0 & 0 & 0 & - & - \\
$\begin{array}{c}\text { Household } \\
\text { contacts }\end{array}$ & 15 & 14 & $93 \cdot 3$ & 3 & 3 & 6 & 2 & 324 & 3.92 \\
$\begin{array}{c}\text { Lepromatous } \\
\text { patients }\end{array}$ & 48 & 48 & $100 \cdot 0$ & 5 & 13 & 12 & 18 & 550 & $4 \cdot 17$ \\
\hline
\end{tabular}

* Total number of sera.

$\dagger$ Three individuals with detectable antibody at time 0 were excluded. 
Table 2. FLA-ABS results according to time after lepromin injection with previous demonstrable anti-M. leprae antibody

\begin{tabular}{ccrrrrr}
\hline & & \multicolumn{6}{c}{ Time (days) } \\
$n$ & 0 & 21 & 45 & 90 & 180 & 365 \\
\hline 1 & 160 & 160 & 640 & 160 & 160 & 160 \\
2 & 640 & 2560 & 640 & 640 & 160 & 160 \\
3 & 160 & 640 & 160 & N.S & 160 & 160 \\
Geometric mean & $251 \cdot 2$ & $645 \cdot 7$ & $407 \cdot 0$ & $323 \cdot 0$ & $158 \cdot 5$ & $158 \cdot 5$ \\
S.D & 1.92 & $3 \cdot 1$ & 1.92 & $2 \cdot 0$ & $1 \cdot 0$ & $1 \cdot 0$ \\
& & & & & & \\
\hline
\end{tabular}

N.S. No sample.

also shown. The responses of three persons whose sera were positive before the first lepromin injection were excluded from Table 1. As can be seen in Table 1, the positivity rate reached its highest value by day 21 , while the antibody level, as expressed by the geometric mean of the antibody titre reached its highest response by day 45 . The values of positivity and antibody titre decreased rapidly becoming completely negative by 365 days. The antibody response to lepromin injection was absent in a group of 4 individuals $(11.8 \%)$ who were negative throughout the study.

The results obtained with the sera of 3 individuals who were positive before the lepromin injection are shown in Table 2. In these, the geometric mean of the antibody titre reached its highest level by day 21 and returned to values comparable to their initial response, prior to the lepromin injection, at the end of the study.

\section{Discussion}

Anti-M. leprae antibodies have been observed to persist for a long time in leprosy patients, even after prolonged treatment with dapsone. ${ }^{10}$ Knowing the time of persistence of antibodies induced by a lepromin injection in healthy individuals, should allow us to decide whether antibody in the sera of leprosy household contacts is likely to be due to the Mitsuda skin test or to infection.

The geometric mean of antibody levels at 45 days after the lepromin injection is very similar to that found in our previous study with household contacts of lepromatous patients. From our results it appears that a lepromin injection can rapidly stimulate an anti- $M$. leprae response in the serum of the majority of individuals $(30 / 34 ; 87 \cdot 3 \%)$. Therefore, we can reasonably place confidence in the antibody result if the test is done about 1 year after the lepromin injection.

As previously mentioned, the sera of 3 individuals without known contact 
were positive at the outset and remained so throughout the experiment. This means a positivity rate not due to the lepromin of $8 \cdot 11 \%$ for which we have as yet no explanation.

\section{Acknowledgment}

The authors wish to thank Raúl Cordoví, Mahuel Azcuy and Manuel Galves for their excellent technical assistance. This work was supported by the UNDP/ World Bank/WHO Special Programme for Research and Training in Tropical Diseases.

\section{References}

${ }^{1}$ Harboe M, Closs O. Immunological aspects of leprosy. Immunology 80 Progress in Immunology IV. Academic Press, London, 1232-41.

${ }^{2}$ Harboe M. Radioimmunoassay and other serological tests and their application in epidemiological work. Lepr Rev, 1981; (Suppl. 1): 275-88.

${ }^{3}$ Melsom R, Harboe M, Myrvang B, Godal T, Belehu A. Immunoglobulin class specific antibodies to $M$. leprae in leprosy patients, including the indeterminate group and healthy contacts as a step in the development of methods for diagnosis of leprosy. Clin exp Immunol, 1982; 42 (2): 225-33.

${ }^{4}$ Abe M, Yoshino Y, Saito T. Fluorescent Leprosy Antibody Absorption (FLA-ABS) Test for detecting subclinical infection of Mycobacterium leprae. Int J Lepr, 1980; 48: 109-19.

${ }^{5}$ González-Abreu E, González A, de la Cruz F. Immunofluorescencia indirecta para la detección de anticuerpos anti-M. leprae. Aplicación a un grupo de pacientes y conviventes. Rev Cub Med Trop, 1983; 35: (3).

${ }^{6}$ Abe M, Izumi S, Saito T, Mathur SK. Early serodiagnosis of leprosy by indirect immunofluorescence. Lepr India, 1976; 48: 272-6.

${ }^{7}$ Bharadwaj VP, Ramu G, Desikan KV. Fluorescent leprosy Antibody Absorption (FLA-ABS) Test for early serodiagnosis of leprosy. Lepr India, 1981; 54 (4): 518-24.

${ }^{8} \mathrm{WHO} /$ Report of the fourth meeting of the scientific working group on the immunology of leprosy. TDR/IMMLEP-SWG. (4)/78.3.

${ }^{9}$ Ministerio de Salud Pública. Nuevo Programa de Control de Lepra, Cuba, 1977.

${ }^{10}$ Harboe M, Closs O. A revival of interest in antibodies studies in leprosy. Proc. of the XI Intern. Leprosy Congress, Mexico DF. Nov. 1978. Excerpta Medica, Amsterdam, 1980. 